\title{
Construction of an in vitro bypassed pyruvate decarboxylation pathway using thermostable enzyme modules and its application to $\mathrm{N}$-acetylglutamate production
}

Borimas Krutsakorn ${ }^{1}$, Takashi Imagawa ${ }^{1}$, Kohsuke Honda ${ }^{1,2^{*}}$, Kenji Okano ${ }^{1}$ and Hisao Ohtake ${ }^{1}$

\begin{abstract}
Background: Metabolic engineering has emerged as a practical alternative to conventional chemical conversion particularly in biocommodity production processes. However, this approach is often hampered by as yet unidentified inherent mechanisms of natural metabolism. One of the possible solutions for the elimination of the negative effects of natural regulatory mechanisms on artificially engineered metabolic pathway is to construct an in vitro pathway using a limited number of enzymes. Employment of thermostable enzymes as biocatalytic modules for pathway construction enables the one-step preparation of catalytic units with excellent selectivity and operational stability. Acetyl-CoA is a central precursor involved in the biosynthesis of various metabolites. In this study, an in vitro pathway to convert pyruvate to acetyl-CoA was constructed and applied to N-acetylglutamate production.
\end{abstract}

Results: A bypassed pyruvate decarboxylation pathway, through which pyruvate can be converted to acetyl-CoA, was constructed by using a coupled enzyme system consisting of pyruvate decarboxylase from Acetobacter pasteurianus and the CoA-acylating aldehyde dehydrogenase from Thermus thermophilus. To demonstrate the applicability of the bypassed pathway for chemical production, a cofactor-balanced and CoA-recycling synthetic pathway for $\mathrm{N}$-acetylglutamate production was designed by coupling the bypassed pathway with the glutamate dehydrogenase from $\mathrm{T}$. thermophilus and $\mathrm{N}$-acetylglutamate synthase from Thermotoga maritima. N-Acetylglutamate could be produced from an equimolar mixture of pyruvate and a-ketoglutarate with a molar yield of 55\% through the synthetic pathway consisting of a mixture of four recombinant $E$. coli strains having either one of the thermostable enzymes. The overall recycling number of CoA was calculated to be 27 .

Conclusions: Assembly of thermostable enzymes enables the flexible design and construction of an in vitro metabolic pathway specialized for chemical manufacture. We herein report the in vitro construction of a bypassed pathway capable of an almost stoichiometric conversion of pyruvate to acetyl-CoA. This pathway is potentially applicable not only to $\mathrm{N}$-acetylglutamate production but also to the production of a wide range of acetyl-CoAderived metabolites.

\footnotetext{
* Correspondence: honda@bio.eng.osaka-u.ac.jp

'Department of Biotechnology, Graduate School of Engineering, Osaka University, 2-1 Yamadaoka, Suita, Osaka 565-0871, Japan

2PRESTO, Japan Science and Technology Agency (JST), 4-1-8 Honcho, Kawaguchi, Saitama 332-0012, Japan
}

\section{Biomed Central}

(c) 2013 Krutsakorn et al.; licensee BioMed Central Ltd. This is an open access article distributed under the terms of the Creative Commons Attribution License (http://creativecommons.org/licenses/by/2.0), which permits unrestricted use, distribution, and reproduction in any medium, provided the original work is properly cited. 


\section{Background}

The integration of diverse biocatalytic modules to expand the versatility of fermentation-based industries has been widely employed for the production of biofuel, pharmaceuticals, and other useful chemicals [1]. However, these "metabolic engineering" approaches often suffer from flux imbalances because the naturally occurring translational and transcriptional regulation mechanisms fail to appropriately function in artificially engineered cells $[2,3]$. One possible approach to overcome this limitation is to construct an in vitro metabolic pathway in which only a limited number of enzymes involved in the pathway-of-interest are used as catalytic modules. In vitro systems offer a number of potential advantages over the conventional fermentation-based production processes such as predictable production yield, operational flexibility, and scalability of the reaction $[4,5]$. However, the enzyme isolation generally requires laborious, costly, and time-consuming procedures, and thus little attention has been paid to the practical application of in vitro metabolic engineering approaches. Recently, we reported a simple approach to construct an in vitro artificial metabolic pathway using thermostable biocatalytic modules [6,7]. The basic procedure consists of the following four steps: 1) selection of suitable thermostable enzymes; 2) expression of the enzymes in mesophilic hosts (e.g. Escherichia coli); 3) preheating the cell suspension at high temperature; and 4) assembly of the catalytic modules at an experimentally optimized ratio to achieve stoichiometric production. The denaturation of indigenous enzymes at high temperatures results in a one-step preparation of highly selective and thermostable biocatalytic modules. The membrane structure of E. coli cells is partially or entirely disrupted at high temperatures, and consequently, better accessibility between the enzymes and substrates can be achieved [8].

Acetyl-CoA is a key precursor for the biosynthesis of a wide variety of industrially useful metabolites. In the mevalonate pathway, acetyl-CoA is carboxylated and conjugated to form various isoprenoid and terpenoid compounds that can be used as flavors, fragrances, and anticancer drugs [9]. Condensation of two acetyl-CoA units leads to the formation of acetoacetyl-CoA, which serves as a C4 backbone for polyhydroxyalkanoates and butanol biosynthesis [10-12]. Acetyl-CoA production tends to be a ratelimiting step of artificially engineered pathways to produce target compounds because acetyl-CoA serves a central intermediate of a wide range of naturally occurring metabolic pathways and thus is subjected to depletion when it is routed into co-existing pathways [2].

In natural metabolism, acetyl-CoA is mainly generated from pyruvate via three routes. Most aerobic microorganisms use the large protein complex of pyruvate dehydrogenase (PDH) to produce acetyl-CoA [13]. Alternatively, pyruvate-ferredoxin oxidoreductase (PFOR) plays an important role in the oxidative decarboxylation of pyruvate in some anaerobic bacteria and hyperthermophilic achaea [14-16]. Pyruvate formate-lyase (PFL) is another key enzyme involved in the carbohydrate metabolism of anaerobic microorganisms [17,18]. However, none are readily available in in vitro production systems. $\mathrm{PDH}$ is one of the largest protein complexes and consists of multiple copies of three or four subunits [19]. For example, the PDH of E. coli consists of a central cubic core composed of 24 molecules of dihydrolipoamide acetyltransferase (E2), onto which up to 24 copies of pyruvate dehydrogenase (E1) and 12 copies of dihydrolipoamide dehydrogenase (E3) are assembled [19]. To our knowledge, there have been no reports on the functional expression of the complete form of PDH in heterologous hosts probably owing to their highly complex nature. PFORs require specific redox partner proteins, namely ferredoxin and ferredoxin reductase, to exert their catalytic abilities. In in vitro systems, the enzymes and the partner proteins freely diffuse in the reaction mixture, resulting in less frequent interactions between them. In addition, the poor oxygen tolerance of PFOR results in operational limitations for its in vitro use. Similarly, PFL is highly sensitive to oxygen stress [20].

To overcome these limitations, in this study, we constructed an in vitro bypassed pathway capable of converting pyruvate to acetyl-CoA using an enzyme couple of thermostable pyruvate decarboxylase and CoAacylating aldehyde dehydrogenase. Owing to the absence of a co-existing pathway, an almost stoichiometric production of acetyl-CoA could be achieved through the in vitro pathway. Furthermore, the performance of this pathway was assessed by integration to an artificial pathway for the production of $\mathrm{N}$-acetylglutamate (NAG), which can be used as an ingredient in the cosmetic industry as an anti-odor compound and skin moisturizer [21,22].

\section{Results}

\section{Construction of the bypassed pyruvate decarboxylation} pathway

A bypassed pyruvate decarboxylation pathway was designed by using an enzyme couple of pyruvate decarboxylase and CoA-acylating aldehyde dehydrogenase (Figure 1). Among microbial pyruvate decarboxylases, those from mesophilic bacteria, including Zymomonas mobilis [23] and Acetobacter pasteurianus [24], are biochemically well characterized. Although BLAST searches of the genomic sequences of (hyper)thermophiles gave no hits when the amino acid sequences of these enzymes were used as queries, the pyruvate decarboxylase from $A$. pasteurianus ( $A p \mathrm{PDC}$ ) has been reported to have a relatively high thermal stability with a half-life of $2 \mathrm{~h}$ at $60^{\circ} \mathrm{C}[24,25]$. The CoA-acylating aldehyde dehydrogenase was obtained from those involved in the gene-expression library of Thermus thermophilus 


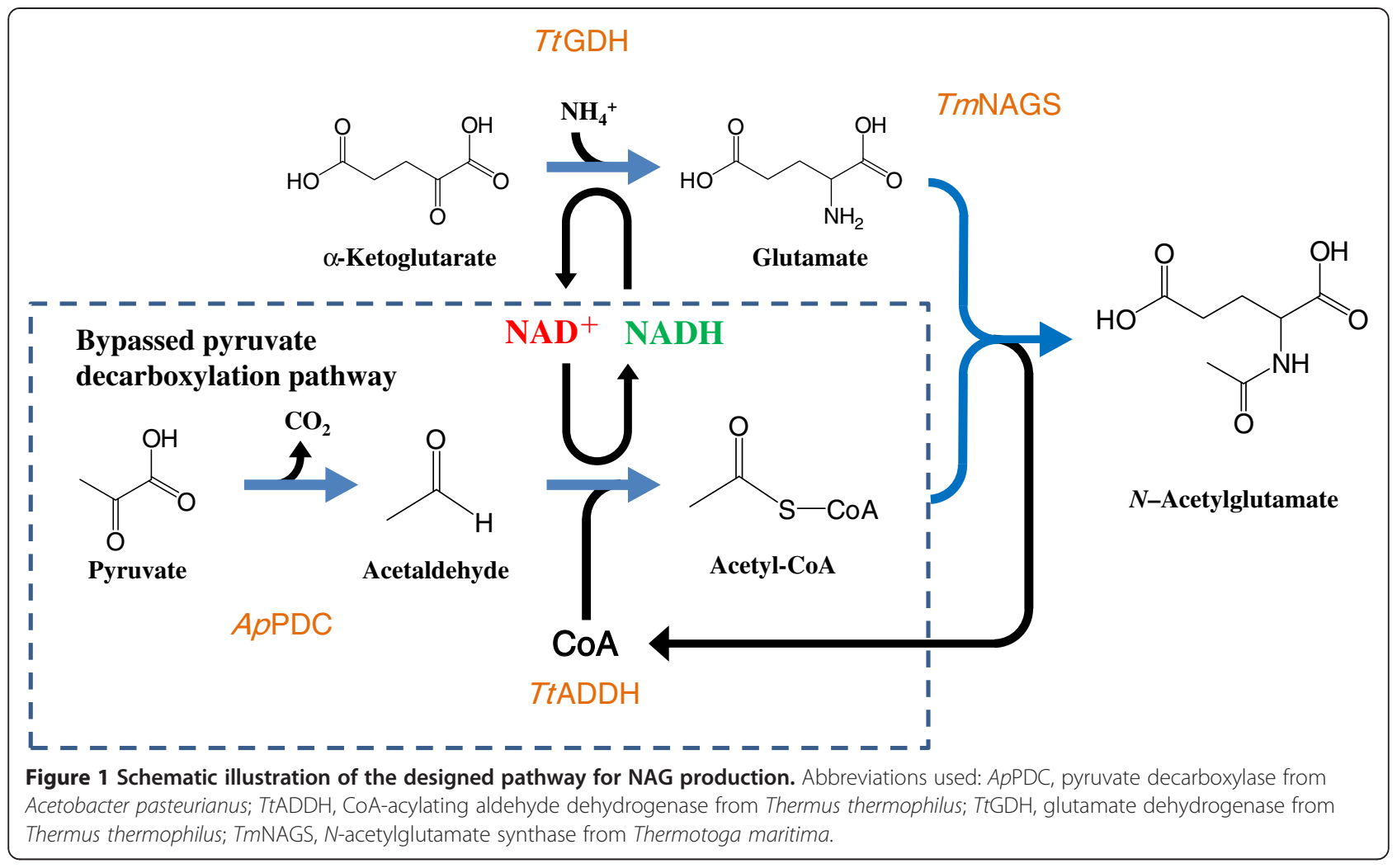

HB8 [26] and designated as TtADDH. We found that TtADDH could catalyze the oxidation of acetaldehyde in both CoA-dependent (acetyl-CoA-forming) and CoAindependent (acetate-forming) manners (Figure 2). Increased CoA concentration (up to $0.5 \mathrm{mM}$ ) led to the shift in the reaction specificity of the enzyme to the acetylCoA-forming direction (Figure 2). On the other hand, CoA concentration higher than $0.5 \mathrm{mM}$ caused a marked inhibition of the enzyme activity. The CoA concentration of $0.2 \mathrm{mM}$ was used in further studies since no significant difference was observed in the reaction specificity and the activity of TtADDH at CoA concentrations of 0.2 and $0.5 \mathrm{mM}$.

$A p$ PDC could retain more than $60 \%$ of its activity after incubation at $50^{\circ} \mathrm{C}$ for $4 \mathrm{~h}$, whereas no apparent decrease was observed in the activity of $T t \mathrm{ADDH}$ at $50^{\circ} \mathrm{C}$ (Figure $3 \mathrm{a}$ and $\mathrm{b})$. Conversely, the activities of both enzymes steeply declined at an incubation temperature of $60^{\circ} \mathrm{C}$ or higher. Thus, a reaction temperature of $50^{\circ} \mathrm{C}$ was used for further studies.

When the heat-treated cells having $A p P D C$ and $T t$ ADDH were incubated with an equimolar mixture of pyruvate, $\mathrm{NAD}^{+}$, and $\mathrm{CoA}\left(2 \mathrm{mM}\right.$ each) at $50^{\circ} \mathrm{C}$, acetyl-CoA could be produced with a molar yield of $65 \%$ (Figure 4). A relatively slow production rate observed in the initial $2 \mathrm{~h}$ is probably attributed to the inhibitory effect of the high initial concentration of CoA on TtADDH.

\section{Design of the NAG production pathway}

The bypassed pyruvate decarboxylation pathway was integrated into a newly designed synthetic pathway for NAG production to evaluate its applicability to chemical production (Figure 1). In the designed pathway, NAG is

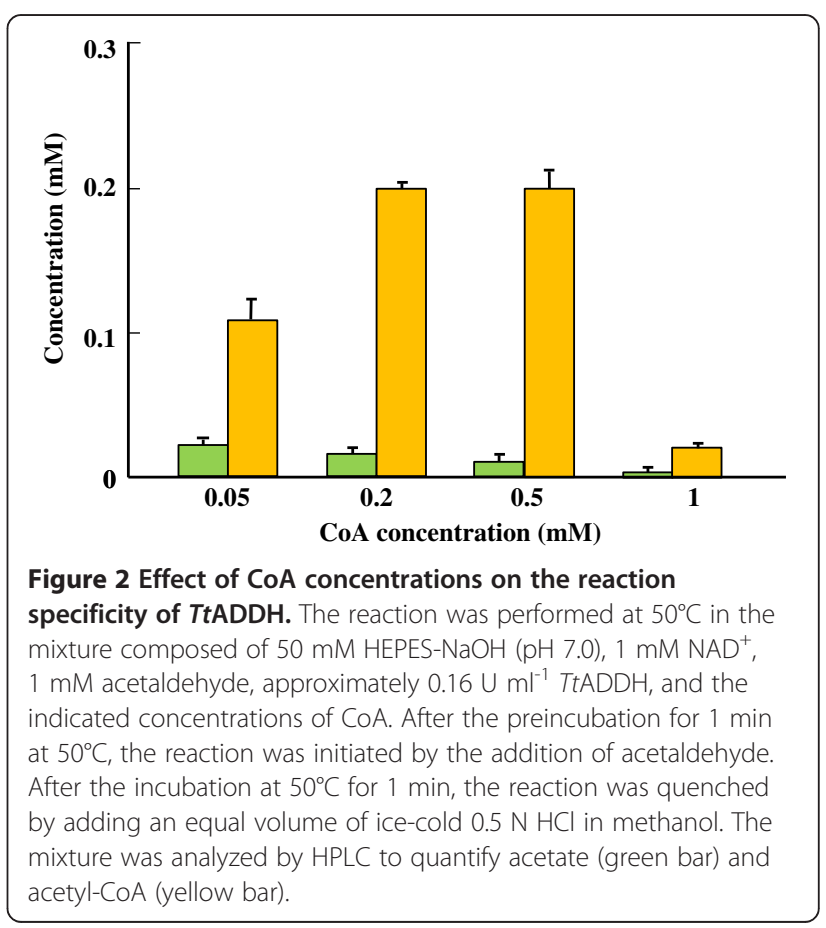




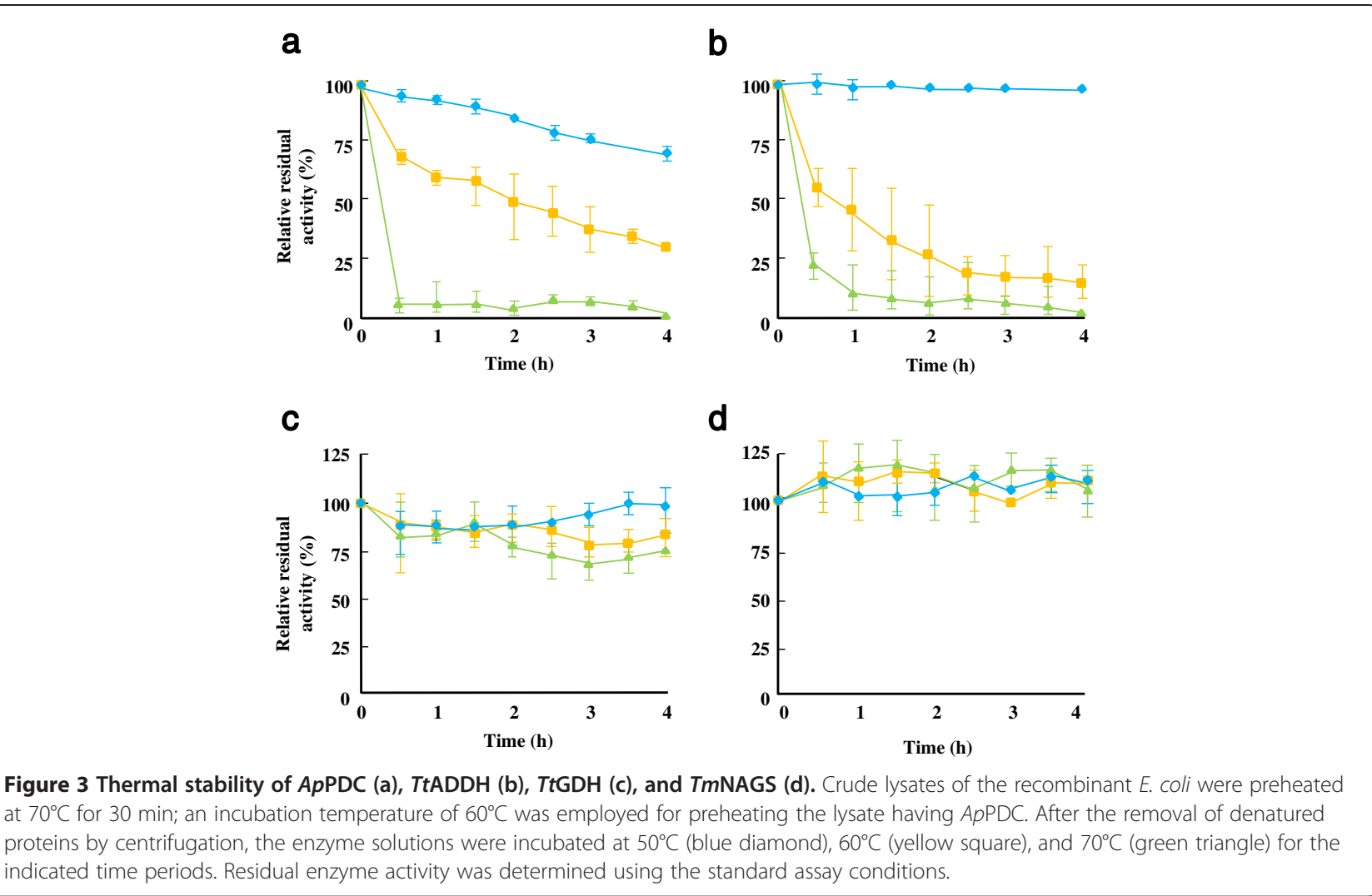

produced through transacetylation from acetyl-CoA to glutamate catalyzed by $\mathrm{N}$-acetylglutamate synthase (NAGS). CoA molecules released by the acetylation of glutamate can be recycled for the synthesis of acetyl-CoA in the bypassed pyruvate decarboxylation pathway. The

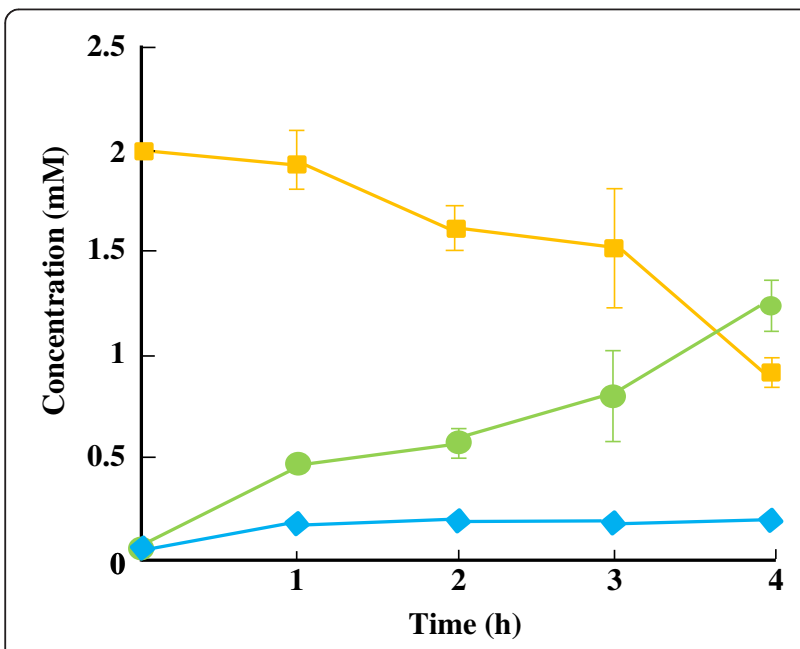

Figure 4 Acetyl-CoA production through the bypassed pyruvate decarboxylation pathway. Heat-treated cells of recombinant E. coli having ApPDC and TtADDH (approximately 8 and $4 \mathrm{mg} \mathrm{ml}^{-1}$, respectively) were incubated at $50^{\circ} \mathrm{C}$ with $2 \mathrm{mM}$ each of pyruvate, $\mathrm{NAD}^{+}$, and CoA. Acetyl-CoA (green circle), CoA (yellow square) and acetate (blue diamond) concentrations were quantified by HPLC. thermostable NAGS, which is involved in the arginine biosynthesis pathway of Thermotoga maritima, is well characterized [27], therefore, the NAGS from T. maritima was selected as the module to construct the pathway and designated TmNAGS.

Unlike natural metabolic pathways, which are equipped with a complete enzyme apparatus for the de novo synthesis of cofactors, indigenous regeneration of redox cofactors is necessary to facilitate the economic feasibility of in vitro production processes $[4,6]$. To achieve balanced $\mathrm{NAD}^{+} / \mathrm{NADH}$ consumption and regeneration, the glutamate dehydrogenase of $T$. thermophilus (TtGDH) was integrated into the NAG production pathway. The enzyme can use $\alpha$-ketoglutarate, an inexpensive material, as a cosubstrate for the re-oxidation of NADH and to produce glutamate, which can be directly used as the substrate for TmNAGS. Thermal stability analysis of TmNAGS and TtGDH demonstrated that they can be used at $50^{\circ} \mathrm{C}$ for at least $4 \mathrm{~h}$ without a significant loss of their activities (Figure $3 \mathrm{c}$ and d).

\section{NAG production}

Activities of $A p \mathrm{PDC}$, TtADDH, TtGDH, and TmNAGS were assessed under the standard assay conditions at a substrate concentration of $0.2 \mathrm{mM}$. One unit (U) of either enzyme was defined as the amount capable of product formation at a rate of $1.0 \mu \mathrm{mol} \mathrm{min}{ }^{-1}$. Enzyme activities were 
assessed at various pHs using the crude extracts of recombinant $E$. coli cells (Table 1 ). The pH profiles of the enzymes revealed that the total protein concentration in the mixture of the crude extracts containing $0.04 \mathrm{U} \mathrm{ml}^{-1}$ of each enzyme can be minimized at pH 7.0.

The flux through the bypassed pyruvate decarboxylation pathway could be determined by incubating an enzyme mixture of $A p P D C$ and TtADDH with $0.2 \mathrm{mM}$ each of pyruvate, $\mathrm{CoA}$, and $\mathrm{NAD}^{+}$, and monitoring the concomitant production rate of NADH at $340 \mathrm{~nm}$. When equal units $\left(0.04 \mathrm{U} \mathrm{ml}^{-1}\right)$ of the enzymes were used, the initial NADH production rate was lower than the expected value of $0.04 \mu \mathrm{mol} \mathrm{min} \mathrm{ml}^{-1}$. In the constructed pathway, the actual concentration of acetaldehyde, which is generated by $A p P D C$ and then used as the substrate for TtADDH, was kept at a lower level than those used in the standard assay, and thus TtADDH failed to catalyze the reaction at the expected rate. We increased the TtADDH concentration in the reaction mixture in a stepwise manner, and found that the expected NADH production rate of $0.04 \mu \mathrm{mol} \mathrm{min}{ }^{-1} \mathrm{ml}^{-1}$ could be achieved by using $0.09 \mathrm{U}$ $\mathrm{ml}^{-1}$ of TtADDH.

The direct production of NAG from pyruvate and $\alpha$-ketoglutarate was performed by using a mixture of heattreated recombinant cells having the experimentally determined amounts of enzymes to achieve a production rate of $0.04 \mu \mathrm{mol} \mathrm{ml}^{-1} \mathrm{~min}^{-1}$ (i.e. $0.04 \mathrm{U} \mathrm{ml}^{-1}$ each of ApPDC, TtGDH, and TmNAGS, and $0.09 \mathrm{U} \mathrm{ml}^{-1}$ of TtADDH). The reaction was performed in a mixture containing $0.2 \mathrm{mM}$ each of pyruvate, $\alpha$-ketoglutarate, L-glutamate, and CoA. A mixture of pyruvate, $\alpha$-ketoglutarate, and $\mathrm{NH}_{4} \mathrm{Cl}$ was continuously supplied into the reaction mixture at a rate of $0.04 \mu \mathrm{mol} \mathrm{ml}^{-1} \mathrm{~min}^{-1}$ to keep a constant flux. However, NAG production stopped after $2 \mathrm{~h}$ despite the sufficient thermal stabilities of the enzymes (Figure 5a). The time profile analysis of the pool sizes of the intermediates and cofactors revealed the concentrations of the redox cofactors, $\mathrm{NAD}^{+}$and $\mathrm{NADH}$, decreased time dependently while those of acetaldehyde and $\alpha$-ketoglutarate remarkably increased (Figure $5 \mathrm{~b}$ ). These facts implied that the thermal decomposition of the redox cofactors led to the decrease in the catalytic performance of $\operatorname{NAD}(\mathrm{H})$ dependent enzymes, TtADDH and TtGDH. Moreover, owing to its highly volatile nature, acetaldehyde accumulation likely led to the loss in the NAG production yield through the constructed pathway. On the basis of these observations, a NAG production assay was conducted with a continuous feeding of $\mathrm{NADH}$ at a rate identical to that of the thermal decomposition $\left(3.3 \mathrm{nmol} \mathrm{ml}^{-1} \mathrm{~min}^{-1}\right)$. Consequently, $5.3 \mathrm{mM}$ of NAG could be produced with a molar yield of $55 \%$ after a 4 -h reaction. The total recycling number of CoA was calculated to be 27 . The time profile of intermediates confirmed that the accumulation of $\alpha$ ketoglutarate and acetaldehyde could be mitigated by the addition of NADH (Figure 5c).

\section{Discussion}

Acetyl-CoA is an essential intermediate for the production of a variety of metabolites; therefore intensive studies have been conducted to increase the intracellular level of acetyl-CoA in artificially engineered microorganisms. Atsumi et al. reported that the increases in the intracellular pool size of acetyl-CoA, which can be achieved by deleting the gene sets of $l d h \mathrm{~A}, a d h \mathrm{E}$, and frd $\mathrm{BC}$ of E. coli, leads to a two-fold increase in 1-butanol production by the engineered cells [2]. Shiba et al. have engineered a pyruvate dehydrogenase bypass pathway in Saccharomyces cerevisiae to increase intracellular acetyl-CoA and to improve the production level of amorphadiene, a sesquiterpene precursor for the biosynthesis of the anti-malarial drug artemisinin [28]. Furthermore, Chen et al. have developed an engineered yeast platform for improved acetyl-CoA production and demonstrated its application for $\alpha$-santalene production [12].

Previously, we reported a simple approach to construct an in vitro artificial metabolic pathway using thermostable biocatalytic modules [6,7]. This approach is, in principle, applicable to any thermostable enzyme as long as it can be functionally expressed in a mesophilic host, and thus is potentially applicable to the biocatalytic manufacture of a wide range of useful compounds. By using this approach, we have constructed a non-ATP-

Table $1 \mathrm{pH}$ profile of enzyme activity

\begin{tabular}{|c|c|c|c|c|c|c|}
\hline \multirow[t]{2}{*}{ Buffer } & \multirow[t]{2}{*}{$\mathrm{pH}$} & \multicolumn{4}{|c|}{ Specific activity $\left(\mathrm{U} \mathrm{mg}^{-1} \text { total protein }\right)^{\mathrm{a}}$} & \multirow[t]{2}{*}{ Total protein concentration $\left(\mathrm{mg} \mathrm{m}^{-1}\right)^{\mathrm{b}}$} \\
\hline & & ApPDC & TtADDH & TtGDH & TmNAGS & \\
\hline MES & 6.0 & 0.046 & 0.067 & 0.164 & 0.154 & 1.97 \\
\hline MES & 6.5 & 0.066 & 0.146 & 0.255 & 0.169 & 1.27 \\
\hline HEPES & 7.0 & 0.078 & 0.137 & 0.291 & 0.208 & 1.13 \\
\hline HEPES & 7.5 & 0.058 & 0.197 & 0.184 & 0.215 & 1.30 \\
\hline Bicine & 8.0 & 0.046 & 0.246 & 0.074 & 0.220 & 1.75 \\
\hline Bicine & 8.5 & 0.025 & 0.450 & 0.026 & 0.227 & 3.37 \\
\hline
\end{tabular}

${ }^{a}$ Specific activities are expressed as those from the crude extract of recombinant $E$. coli before the heat treatment.

${ }^{\mathrm{b}}$ Total protein concentrations in the mixture of crude extracts containing $0.04 \mathrm{U}$ of each of the enzyme are calculated. 


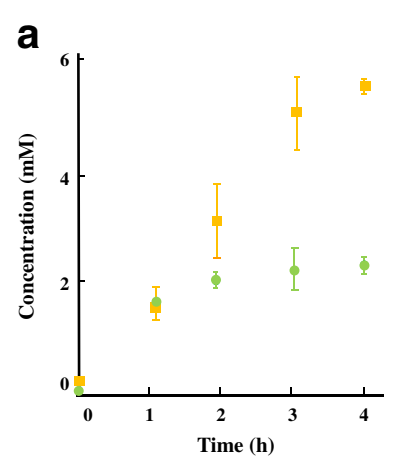

b

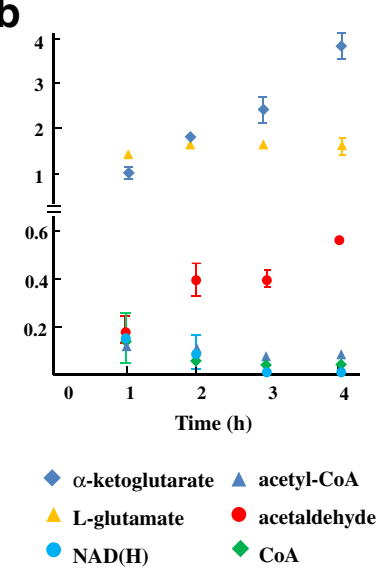

C

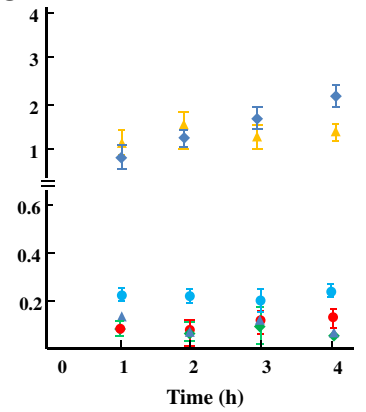

Figure 5 Time course analysis of NAG production. (a) Time profiles of NAG production. Reaction was performed with (yellow square) and without (green circle) NADH feeding at a rate of $3.3 \mu \mathrm{mol} \mathrm{I}^{-1} \mathrm{~min}^{-1}$. (b, and c) Time profiles of the cofactors and intermediates during NAG production in the absence (b) and presence (c) of NADH feeding. The concentration of pyruvate was under the detectable level.

forming chimeric glycolytic pathway and applied it to the direct conversion of glucose to lactate [6] and malate [7]. The construction of an in vitro pyruvate decarboxylation pathway to form acetyl-CoA was one of the key challenges remaining to expand the applicability of this system.

In this study, we constructed an in vitro bypassed pathway for pyruvate decarboxylation by employing an enzyme couple of $A p$ PDC and TtADDH. The bypassed pathway was integrated into the newly designed synthetic pathway for NAG production, in which consumption and regeneration rates of both $\operatorname{NAD}(\mathrm{H})$ and CoA were essentially balanced. The highly traceable nature of the in vitro synthetic pathway enabled us to quantify the intermediate pool sizes without using special equipment and to identify the rate-limiting of the synthetic pathway. The time-course analysis of the intermediates in the NAG-producing pathway indicated that the decrease in the catalytic ability of TtGDH and TtADDH caused by the thermal decomposition of $\mathrm{NAD}(\mathrm{H})$ was the bottleneck. In fact, by continuously supplying NADH to the reaction mixture, 5.4 mM NAG could be produced with a molar yield of $55 \%$ and a CoA-recycling number of 27 could be achieved. The operational stability of the in vitro production system would be improved by the screening and employment of a thermostable glutamate dehydrogenase with lower $K_{\mathrm{m}}$ for $\mathrm{NAD}(\mathrm{H})$. However, the intermediate analysis indicated that accumulation of $\alpha$ ketoglutarate was still not insignificant even when NADH was supplied (Figure 5c). This can be explained by the inhibitory effect of NAG on TtGDH (Figure 6). Although in vitro synthetic pathways are independent of transcriptional and translational regulatory mechanisms of living cells, allosteric regulation cannot be necessarily eliminated. Protein engineering approaches or the substitution with another enzyme module that is less sensitive to allosteric effects would be a straightforward way to eliminate the effect of allosteric inhibition. In fact, we previously demonstrated that the inhibitory effect of $\mathrm{NAD}^{+}$on lactate production through the chimeric glycolytic pathway can be eliminated by changing the $\mathrm{NAD}^{+}$-sensitive lactate dehydrogenase to malate/lactate dehydrogenase [6]. Use of a NAG-insensitive thermophilic glutamate dehydrogenase would be needed to achieve a higher titer of NAG production through the synthetic pathway.

Another possible approach to mitigate the effect of product inhibition is the employment of a continuous product recovery system. Recently, we reported that the pretreatment of recombinant $E$. coli cells having a thermophilic fumarase with a low concentration glutaraldehyde $(\sim 0.15 \mathrm{vol} \%)$ can consolidate the membrane

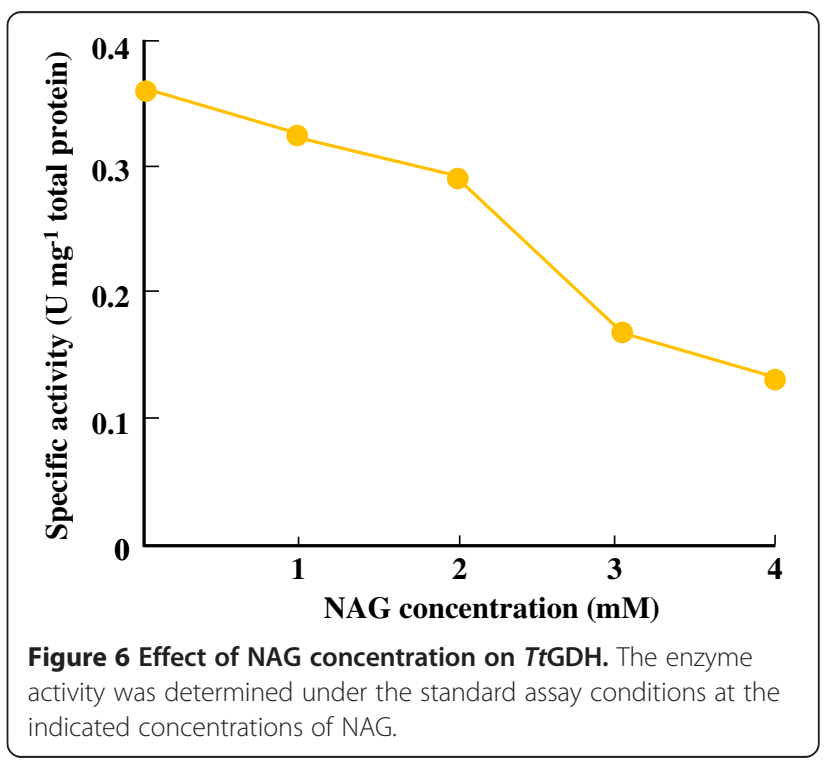


structure of the cells and prevent the heat-induced leakage of the enzyme [8]. The glutaraldehyde-treated cells can be used at $70^{\circ} \mathrm{C}$ for more than $10 \mathrm{~h}$ in a continuous reactor equipped with a cell-separation membrane filter. In the conversional fermentation-based processes, the culture broth contains a number of impurities including residual sugars, nutrients, and other organic materials, apart from cell mass. By contrast, in in vitro production systems, the reaction can be performed in a simple buffer solution, and thus the product separation step can be considerably simplified. Development and integration of an on-line product separation system would be a key challenge to eliminate product inhibition and to achieve the long-term operation of the in vitro production system.

\section{Conclusions}

We designed and constructed an in vitro pyruvate decarboxylation pathway capable of converting pyruvate to acetyl-CoA using an enzyme couple of $A p$ PDC and TtADDH. To demonstrate the applicability of the bypassed pathway to chemical production, the pathway was coupled with TtGDH and TmNAGS to construct a cofactor-balanced and CoA-recycling pathway for NAG production. The highly traceable nature of the in vitro pathway enabled us to readily identify the rate-limiting enzyme. Consequently, $5.4 \mathrm{mM}$ of NAG could be produced through the pathway with a molar yield of $55 \%$ and a CoA-recycling number of 27 . The bypassed pathway constructed in this study would be widely applicable to the production of other acetyl-CoA-derived chemicals including $n$-butanol, polyhydroxyalkanoates, and isoprenoids.

\section{Materials and methods \\ Bacterial strain and plasmid}

The expression plasmids encoding TtADDH (Genebank accession number, YP_145486.1) and TtGDH (YP_144842.1) were obtained from the RIKEN T. thermophilus HB8 expression plasmid set [26]. The gene coding for ApPDC (YP_005499956.1) was amplified by PCR from the chromosomal DNA of $A$. pasteurianus using the following primers: 5'-AACATATGACCTATACTGT TGGCAT-3' (the NdeI restriction site is shown in italics) and 5'-TTCTCGAGTCAGGCCAGAGTCGTC TTGC-3' (the XhoI restriction site is shown in italics). The amplified DNA was digested with NdeI and $\mathrm{XhoI}$ and inserted into the corresponding restriction sites of pET21a (Novagen, Madison, WI, USA). Similarly, the gene encoding TmNAGS (NP_229580.1) was amplified from the chromosomal DNA of $T$. maritima using a primer pair of 5'-AACATATGT TCACTCCCAGGGGTTT-3' (the NdeI restriction site is shown italics) and $5^{\prime}$-TTGAATTCTCATGTTCTG
TACCTCCCGT-3' (the EcoRI restriction site is shown italics), and then introduced into pET21a. The expression vectors were separately introduced in E. coli Rosetta2 (DE3) (Novagen). Recombinant cells were cultivated aerobically at $37^{\circ} \mathrm{C}$ in Luria-Bertani (LB) media supplemented with $50 \mu \mathrm{g} \mathrm{ml}^{-1}$ ampicillin and $30 \mu \mathrm{g} \mathrm{ml}^{-1}$ chloramphenicol. Isopropyl- $\beta$-D-1-thiogalactopyranoside was added to the culture at a final concentration of $0.2 \mathrm{mM}$ in the late-log phase. The cells were harvested by centrifugation and washed once with $50 \mathrm{mM}$ 4-(2-hydroxyethyl)-1piperazineethanesulfonic acid (HEPES)- $\mathrm{NaOH}$ buffer ( $\mathrm{pH}$ 7.0).

\section{Enzyme preparation}

Recombinant cells were suspended in an appropriate volume of $50 \mathrm{mM}$ HEPES-NaOH (pH 7.0) and disrupted using an UD-201 ultrasonicator (Kubota, Osaka, Japan) at $80 \mathrm{~W}$ for $2 \mathrm{~min}$. Cell debris were removed by centrifugation at $12,000 \times g$ at $4{ }^{\circ} \mathrm{C}$ for $10 \mathrm{~min}$. Protein concentration in the crude lysates was measured using a Bio-Rad assay system (Bio-Rad, Hercules, CA, USA) with bovine serum albumin as the standard. The resulting crude lysates were incubated at $70^{\circ} \mathrm{C}$ for $30 \mathrm{~min}$ to inactivate the indigenous enzymes. An incubation temperature of $60^{\circ} \mathrm{C}$ was employed for the heat treatment of the lysate with $A p$ PDC. The heat-treated lysates were centrifuged again to remove the denatured protein and then the supernatants were used as enzyme solutions.

\section{Enzyme assay}

All assays were performed at $50^{\circ} \mathrm{C}$ in $50 \mathrm{mM}$ HEPES$\mathrm{NaOH}$ (pH 7.0) supplemented with $100 \mathrm{mM} \mathrm{KCl}$ and $10 \mathrm{mM} \mathrm{MgCl} 2$ unless otherwise stated. Activities of $A p \mathrm{PDC}, T t \mathrm{ADDH}$, and TtGDH were spectrophotometrically determined by monitoring the consumption or formation rate of NADH at $340 \mathrm{~nm}$. TtADDH was assayed in the buffer containing $0.2 \mathrm{mM} \mathrm{NAD}^{+}, 0.2 \mathrm{mM}$ $\mathrm{CoA}$, and an appropriate amount of the enzyme. After the preincubation at $50^{\circ} \mathrm{C}$ for $2 \mathrm{~min}$, the reaction was started by the addition of acetaldehyde at a final concentration of $0.2 \mathrm{mM}$, and the reduction of $\mathrm{NAD}^{+}$was monitored at $340 \mathrm{~nm}$. The activity of $T t \mathrm{GDH}$ was assessed in a similar manner by monitoring the oxidation of NADH upon the reduction of $0.2 \mathrm{mM} \alpha$-ketoglutarate. ApPDC activity was assessed by coupling with TtADDH. After the preincubation of the enzymes at $50^{\circ} \mathrm{C}$ in the buffer containing $0.2 \mathrm{mM} \mathrm{NAD}^{+}, 0.2 \mathrm{mM} \mathrm{CoA}$, and an excess amount of TtADDH, the reaction was initiated by the addition of $0.2 \mathrm{mM}$ pyruvate and monitored at $340 \mathrm{~nm}$.

TmNAGS activity was assessed by determining the NAG production rate by high-performance liquid chromatography (HPLC). The appropriate amount of enzyme solution was incubated at $50^{\circ} \mathrm{C}$ in the buffer containing $0.2 \mathrm{mM}$ each of L-glutamate and acetyl-CoA. The 
reactions were quenched by the addition of an equal volume of ice-cold methanol. HPLC analysis was performed as described below. One unit (U) of the enzyme was defined as the amount capable of product formation at a rate of $1 \mu \mathrm{mol} \mathrm{min}{ }^{-1}$.

\section{NAG production}

The basal reaction mixture was composed of $100 \mathrm{mM}$ $\mathrm{KCl}, 10 \mathrm{mM} \mathrm{MgCl}_{2}, 0.2 \mathrm{mM} \mathrm{CoA}, 0.2 \mathrm{mM} \mathrm{NAD}^{+}$, $0.2 \mathrm{mM} \mathrm{NADH}$, and $50 \mathrm{mM}$ HEPES-NaOH (pH 7.0). Recombinant cells were suspended in $50 \mathrm{mM}$ HEPES$\mathrm{NaOH}\left(\mathrm{pH} \mathrm{7.0)}\right.$ ) and heated at $70^{\circ} \mathrm{C}$ for $30 \mathrm{~min}$, although an incubation temperature of $60^{\circ} \mathrm{C}$ was employed for the heat-treatment of $E$. coli having $A p P D C$. The heattreated suspensions of $E$. coli having ApPDC, TtADDH, $T t G D H$, and TmNAGS were added into the reaction mixture at final concentrations of 16, 7, 50, and $10 \mathrm{mg}$ (wet weight cells) $\mathrm{ml}^{-1}$, respectively. The mixture $(8 \mathrm{ml})$ was placed in a 10-ml rubber-capped cylindrical vessel and stirred in a water bath kept at $50^{\circ} \mathrm{C}$. The reaction was initiated by adding the indicated concentrations of substrates and the intermediates. The feeding of a substrate solution consisting of $100 \mathrm{mM}$ each of $\alpha$-ketoglutarate, pyruvate, and $\mathrm{NH}_{4} \mathrm{Cl}$ was started using a LC-20 AD solvent delivery unit (Shimadzu, Kyoto, Japan). The feeding rate was kept at $3.2 \mu \mathrm{min}^{-1}\left(=0.04 \mu \mathrm{mol} \mathrm{ml} \mathrm{min}^{-1}\right)$. Simultaneously, $0.2 \mathrm{mM}$ pyruvate, $0.2 \mathrm{mM}$ acetyl-CoA, $0.2 \mathrm{mM} \alpha-$ ketoglutarate, $0.2 \mathrm{mM}$ L-glutamate, and $100 \mathrm{mM} \mathrm{NH}_{4} \mathrm{Cl}$ were added to the reaction mixture to maintain the constant pool sizes. The reaction was quenched at timed intervals by the addition of an equal volume of pre-cooled methanol and analyzed to determine the product and intermediates.

\section{Analytical methods}

Acetate, $\alpha$-ketoglutarate, pyruvate, and NAG were determined by HPLC on two ion exclusion columns connected in tandem as described previously [6]. CoA and acetylCoA were quantified by HPLC using a Cosmosil 5C18ARII column $(4.6 \times 250 \mathrm{~mm}$, Nacalai Tesque, Kyoto, Japan). The column was eluted with $0.1 \%$ (v/v) orthophosphate solution for the initial $2 \mathrm{~min}$ and then with a linear gradient of methanol (0-30 vol\%) for $10 \mathrm{~min}$. The column was maintained at $40^{\circ} \mathrm{C}$ and the flow rate of $1.0 \mathrm{ml} \mathrm{min}^{-1}$ was employed for the elution. The eluent was analyzed with a SPD-20AV UV-VIS detector (Shimadzu) at $254 \mathrm{~nm}$. Aldehydes were fluorescence-labeled with 1,3cyclohexanedione as described elsewhere [29] and determined using HPLC on the same column. The column was eluted at $40^{\circ} \mathrm{C}$ using $30 \%(\mathrm{v} / \mathrm{v})$ acetonitrile at a flow rate of $0.5 \mathrm{ml} \mathrm{min}^{-1}$. The eluent was analyzed with an RF10A fluorometric detector (Shimadzu) at excitation and emission wavelengths of 366 and $440 \mathrm{~nm}$, respectively. NAD $(\mathrm{H})$ and glutamate were quantified using commercial kits as described in the instructions provided by the manufacturers (Biovision, Mountain View, CA, USA and Cosmo Bio, Tokyo, Japan, respectively).

\section{Competing interests}

The authors declare that they have no competing interests.

\section{Authors' contributions}

BK performed the experiments and wrote the manuscript. TI constructed the bypassed pyruvate decarboxylation pathway. $\mathrm{KH}$ designed all the experiments and wrote the manuscript. KO contributed general advice, particularly on the thermophilic microorganisms, as well as edited the manuscript. $\mathrm{HO}$ supervised the work. All authors read and approved the final manuscript.

\section{Acknowledgments}

This work was supported in part by the Japan Science and Technology Agency (JST), PRESTO program. This work was also partly supported by the Japan Society for the Promotion of Science (JSPS), Japanese-German Graduate Externship Program.

Received: 10 July 2013 Accepted: 17 September 2013 Published: 7 October 2013

\section{References}

1. Alper H, Stephanopoulos G: Engineering for biofuels: exploiting innate microbial capacity or importing biosynthetic potential? Nat Rev Microbiol 2009, 7:715-723.

2. Atsumi S, Cann AF, Connor MR, Shen CR, Smith KM, Brynildsen MP, Chou KJY, Hanai T, Liao JC: Metabolic engineering of Escherichia coli for 1-butanol production. Metab Eng 2008, 10:305-311.

3. Kwok R: Five hard truths for synthetic biology. Nature 2010, 463:288-290.

4. Zhang Y-HP: Production of biocommodities and bioelectricity by cell-free synthetic enzymatic pathway biotransformation: challenges and opportunities. Biotechnol Bioeng 2010, 105:663-677.

5. Hodgman CE, Jewett MC: Cell-free synthetic biology: thinking outside the cell. Metab Eng 2012, 14:261-269.

6. Ye X, Honda K, Sakai T, Okano K, Omasa T, Hirota R, Kuroda A, Ohtake H: Synthetic metabolic engineering-a novel, simple technology for designing a chimeric metabolic pathway. Microb Cell Fact 2012, 11:120

7. Ye X, Honda K, Morimoto Y, Okano K, Ohtake H: Direct conversion of glucose to malate by synthetic metabolic engineering. J Biotechnol 2013, 164:34-40.

8. Ninh PH, Honda K, Yokohigashi Y, Okano K, Omasa T, Ohtake H: Development of a continuous bioconversion system using a thermophilic whole-cell biocatalyst. App/ Environ Microbiol 2013, 79:1996-2001.

9. Dewick PM: The biosynthesis of C5-C25 terpenoid compounds. Nat Prod Rep 2002, 19:181-222.

10. Steinbüchel A, Füchtenbusch B: Bacterial and other biological systems for polyester production. Trends Biotechnol 1998, 16:419-427.

11. Bond-Watts BB, Bellerose RJ, Chang MCY: Enzyme mechanism as a kinetic control element for designing synthetic biofuel pathways. Nat Chem Biol 2011, 7:222-227.

12. Chen $Y$, Daviet $L$, Schalk $M$, Siewers $V$, Nielsen J: Establishing a platform cell factory through engineering of yeast acetyl-CoA metabolism. Metab Eng 2013, 15:48-54.

13. Patel MS, Roche TE: Molecular biology and biochemistry of pyruvate dehydrogenase complexes. FASEB J 1990, 4:3224-33.

14. Blamey JM, Adams MWW: Purification and characterization of ferredoxin oxidoreductase from the hyperthermophilic archaeon Pyrococcus furiosus. Biochim Biophys Acta 1993, 1161:19-27.

15. Furdui C, Ragsdale SW: The role of pyruvate ferredoxin oxidoreductase in pyruvate synthesis during autotrophic growth by the Wood-Ljungdahl pathway. J Biol Chem 2000, 275:28494-28499.

16. Furdui C, Ragsdale SW: The roles of coenzyme A in the pyruvate: ferredoxin oxidoreductase reaction mechanism: rate enhancement of electron transfer from a radical intermediate to an iron - sulfur cluster. Biochemistry 2002, 41:9921-9937.

17. Knappe J, Blaschkowski HP, Grobner P, Schmitt T: Pyruvate formate-lyase of Escherichia coli: the acetyl-enzyme intermediate. Eur J Biochem 1974, 50:253-263. 
18. Külzer R, Pils T, Kappl R, Hüttermann J, Knappe J: Reconstitution and characterization of the polynuclear iron-sulfur cluster in pyruvate formate-lyase-activating enzyme. J Biol Chem 1998, 273:4897-4903

19. Yang H, Hainfeld JF, Wall JS, Frey PA: Quaternary structure of pyruvate dehydrogenase complex from Escherichia coli: J Biol Chem 1985, 260:16049-16051.

20. Knappe J, Neugebauer FA, Blaschkowski HP, Ganzler M: Post-translational activation introduces a free radical into pyruvate formate-lyase. Proc Natl Acad Sci U S A 1984, 81:1332-1335.

21. Friedman HH, Halik LK, Schwarz MH: Skin moisturizer. US: Patent 3932622 A; 1976.

22. Van Scott-Eugene J, Yu-Ruey J: Anti-odor compositions and therapeutic use. World Patent 2006, 119283:A2.

23. Dawes EA, Ribbons DW, Large PJ: The route of ethanol formation in Zymomonas mobilis. Biochem J 1966, 98:795-803.

24. Raj KC, Ingram LO, Maupin-Furlow JA: Pyruvate decarboxylase: a key enzyme for the oxidative metabolism of lactic acid by Acetobacter pasteurianus. Arch Microbiol 2001, 176:443-451.

25. Gocke D, Graf T, Brosi H, Frindi-Wosch I, Walter L: Comparative characterization of thiamine diphosphate-dependent decarboxylases. J Mol Catal B Enzym 2009, 61:30-35.

26. Yokoyama S, Matsuo Y, Hirota H, Kigawa T, Shirouzu M, Kuroda Y, Kurumizaka H, Kawaguchi S, Ito Y, Shibata T, Kainosho M, Nishimura Y, Inoue Y, Kuramitsu S: Structural genomics projects in Japan. Nat Struct Biol 2000, 7:943-945.

27. Van de-Casteele M, Demarez M, Legrain C, Glansdorff N, Piérard A: Pathways of arginine biosynthesis in extreme thermophilic archaeo- and eubacteria. J Gen Microbiol 1990, 136:1177-1183.

28. Shiba Y, Paradise EM, Kirby J, Ro D-K, Keasling JD: Engineering of the pyruvate dehydrogenase bypass in Saccharomyces cerevisiae for high-level production of isoprenoids. Metab Eng 2007, 9:160-168.

29. Stahovec WL, Mopper K: Trace analysis of aldehydes by pre-column fluorigenic labeling with 1,3-cyclohexanedione and reversed-phase highperformance liquid chromatography. J Chromatogr A 1984, 298:399-406.

doi:10.1186/1475-2859-12-91

Cite this article as: Krutsakorn et al:: Construction of an in vitro bypassed pyruvate decarboxylation pathway using thermostable enzyme modules and its application to $\mathrm{N}$-acetylglutamate production. Microbial Cell Factories 2013 12:91.

\section{Submit your next manuscript to BioMed Central and take full advantage of:}

- Convenient online submission

- Thorough peer review

- No space constraints or color figure charges

- Immediate publication on acceptance

- Inclusion in PubMed, CAS, Scopus and Google Scholar

- Research which is freely available for redistribution 